Jaqueline Pereira Ventura

Universidade Federal Fluminense, UFF

E-mail: jaqventura@uol.com.br

(9) http://orcid.org/0000-0001-9548-253X

Thays Espindola Cruz

Universidade Federal Fluminense, UFF

E-mail: espindolathays@id.uff.br

http://orcid.org/0000-0002-9672-8471

Catharinna Ferreira da Costa Marques

Universidade Federal Fluminense, UFF

E-mail: catharinnacosta@outlook.com

http://orcid.org/0000-0002-3046-9390

Recebido em: 02/07/2019

Aprovado em: 05/09/2019

\section{As pesquisas sobre o ensino médio na EJA: uma análise de artigos da plataforma de periódicos da \\ CAPES}

\author{
Jaqueline Pereira Ventura \\ Thays Espindola Cruz \\ Catharinna Ferreira da Costa Marques
}

\section{Resumo}

Este trabalho apresenta um estudo bibliográfico a partir do levantamento, da sistematização e da análise da produção acadêmica sobre a Educação de Jovens e Adultos no Ensino Médio (EJA/EM). A proposta é refletir sobre as temáticas recorrentes, bem como sobre as principais questões e referências teóricas acerca do Ensino Médio na modalidade EJA mediante uma abordagem quantitativa $\mathrm{e}$ qualitativa. Tal levantamento foi realizado entre os artigos disponíveis no Portal de Periódicos da Coordenação de Aperfeiçoamento de Pessoal de Nível Superior (Capes). Foram selecionados 43 artigos, organizados em 3 eixos temáticos: 1) Ensino Médio na modalidade EJA; 2) Programa Nacional de Integração da Educação Profissional com a Educação Básica na Modalidade de Educação de Jovens e Adultos (Proeja); 3) EJA/EM como locus da pesquisa. Os resultados deste estudo evidenciam que essa etapa da EJA ainda não se configura como objeto principal de pesquisa, mas é frequentemente citada apenas como locus da investigação ou compreendida a partir do Proeja.

Palavras-chave: Educação de Jovens e Adultos (EJA). Ensino Médio (EM). Programa Nacional de Integração da Educação Profissional com a Educação Básica na Modalidade de Educação de Jovens e Adultos no Ensino Médio (Proeja/EM). 
Abstract

Keywords:

Youth and Adult Education

(YAE).

School

High

Program

for the

Integration of

Professional

Education with

Basic Education

in the Youth and

Adult Education

Modality

(Proeja/HS).

\section{Resumen}

Palabras clave:

Educación de jóvenes y adultos (EJA). Enseñanza media (EM). Programa nacional de integración de la educación profesional con la educación básica en la modalidad de educación de jóvenes y adultos en la enseñanza media

(Proeja/EM)
Research on secondary education in the youth and adult education (YAE): an analysis of articles in the scientific journals in CAPES platform

This work presents a bibliographic study from the survey, the systematization and the analysis of the academic production on the Youth and Adult Education in the Secondary Education (YAE/ SE). The proposal is to think over the recurring themes, as well as the main questions and theoretical references on secondary education in the YAE modality through quantitative and qualitative approach. This survey was carried out on the articles available in the Scientific Journals Portal of the Coordination of Improvement of Higher Education Personnel (CAPES - Coordenação de Aperfeiçoamento de Pessoal de Ensino Superior). 43 articles were selected and organized into three thematic axes: 1) Secondary Education in the YAE modality; 2) National Program for the Integration of Professional Education with Basic Education in the Youth and Adult Education Modality (Proeja - Programa Nacional de Integração da Educação Profissional com a Educação Básica na Modalidade de Educação de Jovens e Adultos); and 3) YAE/SE as research locus. The results of this study evidence that this stage of YAE is still not configured as the main research object, but it is frequently mentioned only as a locus of investigation or understood from the Proeja.

Las pesquisas sobre la enseñanza media en EJA: un análisis de artículos de la plataforma de periódicos de CAPES

Este trabajo presenta un estudio bibliográfico a partir del levantamiento, de la sistematización y del análisis de la producción académica sobre la Educación de Jóvenes y Adultos en la Enseñanza Media (EJA/EM). La propuesta es reflexionar sobre las temáticas comunes, así como sobre las principales cuestiones y referencias teóricas acerca de la Enseñanza Media en la modalidad EJA por medio de un abordaje cuantitativo y cualitativo. Este levantamiento fue realizado entre los artículos disponibles en el Portal de Periódicos de la Coordenação de Aperfeiçoamento de Pessoal de Nível Superior (CAPES). Fueron seleccionados 43 artículos, organizados en tres ejes temáticos: 1) Enseñanza Media en la modalidad EJA; 2) Programa Nacional de Integración de la Educación Profesional con la Educación Básica en la Modalidad de Educación de Jóvenes y Adultos (Proeja); 3) EJA/EM como locus de pesquisa. Los resultados de este estudio señalan que esa etapa de EJA todavía no se vuelve como objeto principal de pesquisa, sino que es a menudo referida sólo como locus de investigación o comprendida a partir del Proeja. 


\section{Introdução}

Neste trabalho, apresentamos um levantamento bibliográfico das abordagens mais recorrentes sobre a Educação de Jovens e Adultos no Ensino Médio (EJA/EM) presentes em artigos disponíveis no Portal de Periódicos da Coordenação de Aperfeiçoamento de Pessoal de Nível Superior (Capes). O intuito é contribuir para o campo de estudos da Educação de Jovens e Adultos (EJA) mediante apresentação e análise de dados obtidos durante a pesquisa. Nosso artigo tem por objetivo identificar e refletir sobre as principais temáticas abordadas no meio científico acerca do Ensino Médio na EJA. Para tanto, a partir dos trabalhos identificados durante o período de coleta na Plataforma Capes, de agosto a setembro de 2018, pautamo-nos na elaboração de eixos/categorias baseados nas principais recorrências desses textos.

O processo de busca realizado no portal da Capes teve por objetivo identificar pesquisas científicas que abordassem a EJA/EM. A primeira etapa da investigação contou com dois movimentos: a utilização das palavras-chave 'Educação de Jovens e Adultos + Ensino Médio' e a leitura de títulos, resumos e introduções, a fim de selecionar os trabalhos que contemplassem o tema. Como resultado desse levantamento, foram obtidos, inicialmente, 1.136 trabalhos. Todavia, cabe ressaltar que esse número é deficitário, uma vez que havia artigos duplicados; artigos que, em sua maioria, tratavam sobre o ensino de alguma disciplina no Ensino Médio/EJA; e artigos que em nada se relacionavam com o tema. Em vista disso, ao final, somente 43 artigos foram escolhidos para a análise posterior.

Diante da pouca produção voltada para a EJA/EM, coletamos artigos que dialogassem com nosso tema mesmo que superficialmente, a fim de trazer uma perspectiva mais ampla. Realizamos a sistematização dos dados de cada texto e também a leitura e a análise dos trabalhos na íntegra. E dividimos os 43 artigos em 3 eixos principais: 1) Ensino médio na modalidade EJA; 2) Programa Nacional de Integração da Educação Profissional com a Educação Básica na Modalidade de Educação de Jovens e Adultos (Proeja); e 3) EJA/EM como locus da pesquisa. Eles foram distribuídos entre as temáticas mais recorrentes, conforme o Quadro 1: 
Quadro 1 - Quantitativo dos artigos levantados por eixo e temática

\begin{tabular}{|c|c|c|c|}
\hline \multicolumn{3}{|c|}{ Eixos/Temáticas } & Quantidade \\
\hline \multicolumn{3}{|c|}{ Análises e avaliações sobre o Ensino Médio na modalidade EJA } & 4 \\
\hline \multicolumn{3}{|c|}{ Proeja } & 21 \\
\hline .1 & & lo integrado & 6 \\
\hline .2 & & os estudantes, desistência e permanência & 3 \\
\hline .3 & & tação e implementação do Proeja & 8 \\
\hline .4 & & ão docente & 2 \\
\hline .5 & & cas diversas & 2 \\
\hline \multicolumn{3}{|c|}{ EJA/EM como locus da pesquisa } & 18 \\
\hline .1 & & trabalho-educação & 3 \\
\hline \multirow{3}{*}{.2} & & cas diversas & 10 \\
\hline & .2 .1 & Educação Básica (Ensino Fundamental e Ensino Médio) & 3 \\
\hline & .2 .2 & Educação Especial & 2 \\
\hline \multicolumn{3}{|c|}{ Total } & 43 \\
\hline
\end{tabular}

Fonte: elaborado pelas autoras.

A fim de melhor explicitar como se procedeu a organização do material, ressaltamos que o Eixo 1 reúne quatro artigos cujo objeto, à exceção de um, que trata de uma proposta curricular para EJA/EM, é o Ensino Médio na modalidade EJA como um elemento que complementa fenômenos verificados no ensino regular ou que torna mais completa a investigação realizada acerca do próprio Ensino Médio.

\section{Resultados: o que dizem os artigos?}

Antes de expor os resultados do levantamento bibliográfico sobre o que diz a produção acadêmica a respeito do Ensino Médio na modalidade EJA, é preciso sublinhar que, a partir da Lei de Diretrizes e Bases da Educação (LDB), Lei no 9.394, de 20 de dezembro de 1996 (BRASIL, 1996), o sistema educacional brasileiro foi dividido em dois níveis: a Educação Básica e o Ensino Superior. A Educação Básica passou a ser estruturada por etapas e modalidades de ensino. Este texto aborda, de forma específica e exclusiva, a etapa do Ensino 
Médio na modalidade EJA. E as Diretrizes Curriculares para Educação de Jovens e Adultos Parecer CNE/CEB no 11, de 10 de maio de 2000 (BRASIL, 2000) - orientam a organização curricular das escolas que ofertam esta modalidade.

Cabe lembrar que a obrigatoriedade do nível médio só ocorreu legalmente em 2009, com a Emenda Constitucional $n^{\circ}$ 59/2009 (BRASIL, 2009), que estendeu a faixa etária da educação obrigatória até os 17 anos, idade correspondente ao Ensino Médio. Por ser a última etapa da Educação Básica, a demanda por esse nível parece pequena, se comparada linearmente com a demanda por Ensino Fundamental (incluindo a alfabetização), mas encobre todos aqueles que ainda estão como demandantes potenciais do Ensino Fundamental por não o ter concluído.

Nosso levantamento procurou identificar como os pesquisadores têm abordado essa temática e o que dizem os artigos que selecionamos. O resultado quantitativo e qualitativo aponta para uma escassez de análises sobre essa etapa na EJA. Chama-nos a atenção o fato de que existem poucas pesquisas sobre os currículos propostos para o Ensino Médio na EJA pelas redes públicas estaduais de ensino, responsáveis diretas pelo Ensino Médio também nesta modalidade.

Salientamos que a maioria dos artigos não menciona o referencial teórico que embasa sua pesquisa. E destacamos também a predominância de análises a partir de relatos de experiências específicas, em detrimento de análises mais amplas sobre o Ensino Médio na modalidade EJA como direito à conclusão da Educação Básica.

Constatamos a ausência quase total de análises sobre a Base Nacional Comum Curricular (BNCC), especialmente as Diretrizes Nacionais Curriculares (DCN) do Ensino Médio e a Lei 13.415, de 16 de fevereiro de 2017 (BRASIL, 2017), que instituiu a reforma desta etapa de ensino, e seus possíveis impactos na EJA. Por exemplo, a possibilidade de que $30 \%$ do Ensino Médio seja ofertado no período noturno e $80 \%$ da EJA seja coberta por atividades realizadas a distância. Acreditamos que essa ausência seja decorrente do fato de a maioria dos textos ser anterior a 2017, ano de aprovação da reforma, e também porque as reflexões que localizamos sobre o currículo da EJA no Ensino Médio estão situadas nas experiências de Proeja, com análises endógenas às experiências do programa.

Observamos que, quando não abordada majoritariamente quanto ao Proeja ou como locus da pesquisa, a EJA/EM é apresentada com a finalidade de trazer dados que complementam fenômenos verificados no ensino regular ou de tornar mais completa a investigação sobre o Ensino Médio como um todo. Depreendemos que o tema central de nossa pesquisa é tratado de forma ainda escassa no meio acadêmico. Apresentaremos, pois, os resultados e as discussões oriundos de nosso processo de investigação. 


\section{Análises e avaliações sobre o Ensino médio na modalidade EJA}

No que se refere aos trabalhos alocados no Eixo 1 - Ensino médio na modalidade EJA, foi possível perceber um fenômeno de secundarização da EJA no meio acadêmico, principalmente na sua última etapa (EM). No sentido de que, para que a modalidade fosse abordada em estudos científicos, precisaria, aparentemente, vir acompanhada de uma análise do ensino regular, não sendo tratada ela mesma como objeto de estudo.

Indubitavelmente, todas essas obras trazem uma grande contribuição para o campo de estudos em Educação. Contudo, o que estamos enfatizando nesta investigação diz respeito a uma falta de autonomia dada à Educação de Jovens e Adultos no âmbito das produções acadêmicas, de forma que ela não tem sido estudada quanto às suas próprias problemáticas.

O primeiro artigo do Eixo 1, Expansão do Ensino Médio: temores sobre a Educação de Jovens e Adultos (GOMES; CARNIELLI, 2003), discute um suposto esvaziamento do ensino regular pela EJA, dentro de um contexto de expansão do Ensino Médio. O texto demonstra, no entanto, que houve um aumento significativo do número de matrículas em ambos os casos, mas que, ainda assim, o Ensino Médio regular concentra uma parcela maior de alunos. Havendo - pela preocupação com o mercado de trabalho e com a continuidade dos estudos - uma migração dentro do próprio ensino regular para o turno da noite, e não para a EJA.

O segundo artigo, Ensino Médio: possibilidades de avaliação (MORAES; ALAVARSE, 2011), analisa a qualidade do Ensino Médio e investiga-o em sua totalidade, abarcando a EJA. Evidencia que os métodos avaliativos qualificadores do Ensino Médio carecem de fidedignidade, uma vez que, embora sejam de suma relevância para o mínimo conhecimento das escolas no Brasil, eles também são limitados em sua própria natureza, pois transferem a responsabilidade da existência de políticas públicas para o desempenho dos alunos, ignorando o contexto de precarização em que a Educação Básica está inserida.

Ao levar em consideração a expansão do processo de escolarização, o texto questiona o caráter democrático da escola perante a qualidade do Ensino Médio, tendo em vista que, embora tenha ocorrido um significativo aumento do número de matrículas, os índices de evasão e de reprovação contradizem esse perfil. E conclui que “[...] o Ensino Médio ainda é uma etapa educacional para poucos no Brasil" (MORAES; ALAVARSE, 2011, p. 831-832).

Diante da constatação de um público reduzido no Ensino Médio regular, o terceiro artigo, Uma análise dos fatores associados à frequência ao Ensino Médio na Educação de Jovens e Adultos (EJA) no Brasil (TAVARES; SOUZA; PONCZEK, 2013), parte do pressuposto de que esse fenômeno se dá em função de uma suposta atração dos jovens pela 
EJA, como se esta os cooptasse. Os autores empreendem uma análise dos fatores relacionados à evasão e ao retorno do Ensino Médio regular e da EJA, bem como do movimento de transferência do ensino regular para essa modalidade da Educação Básica. E concluem que “[...] a EJA rivaliza com o Ensino Médio regular, incentivando alunos em idade correta para cursar o Ensino Médio a migrar para a educação de jovens e adultos” (TAVARES; SOUZA; PONCZEK, 2013, p. 1).

Com isso, podemos notar algumas aproximações entre os três trabalhos. Os dois primeiros partem do mesmo cenário de expansão do Ensino Médio e se preocupam em realizar uma análise do número de matrículas relativo a esse contexto. Chama atenção a ideia defendida no terceiro texto, acerca de um esvaziamento do Ensino Médio regular ocasionado pela migração dos alunos para o Ensino Médio na EJA, que diz respeito exatamente à tese desconstruída no primeiro texto. Este mostra que, apesar do aumento de matrículas em ambos os casos, o ensino regular ainda concentra uma considerável quantidade de alunos, enquanto a EJA permanece sendo uma opção negligenciada e, portanto, com um público reduzido.

Ainda sobre esses dois trabalhos, destacamos a perspectiva pouco crítica com que tratam os problemas apresentados. Por exemplo, ao verificar que os estudantes têm preferido o ensino regular noturno à EJA por considerarem estigmatizados os certificados desta modalidade, o primeiro texto não explora essa atribuição de um caráter pejorativo conferido à EJA, tampouco problematiza o porquê da baixa qualidade de seu ensino ou dos poucos recursos nela investidos, naturalizando, assim, os problemas da EJA.

O terceiro texto, ao constatar a problemática de que muitos jovens têm migrado para a EJA, não se aprofunda em verificar, por exemplo, o processo de juvenilização da modalidade. E o que nos chamou mais a atenção: confere um tom acusatório à EJA, como se o problema estivesse no fato de ela existir. Sem suscitar, portanto, reflexões sobre por que o jovem quer ficar no ensino regular ou, no outro caso, por que quer ir para a EJA. Nesse sentido, os referidos estudos parecem oferecer uma análise pouco aprofundada dos problemas identificados.

Uma última consideração acerca desses dois textos diz respeito a uma grande contradição entre os fenômenos verificados por eles. O texto de Gomes e Carnielli (2003) atribui a permanência dos jovens no Ensino Médio regular ao fato de considerarem a EJA uma modalidade de ensino com qualidade inferior. Já o texto de Tavares, Souza e Ponczek (2013) constata que a EJA é uma opção atrativa para os jovens, verificando uma migração dos alunos do Ensino Médio regular para essa modalidade. Tendo sido publicado o primeiro artigo em 2003 e o outro em 2013, poderíamos supor, de acordo com os fenômenos analisados, que a EJA estaria concentrando um considerável número de matrículas. Contudo, 
o que vemos atualmente é um desmonte da Educação de Jovens e Adultos, com o fechamento de turmas e de escolas.

Por último, o artigo Um novo modelo de EJA para o Ensino Médio no Rio de Janeiro (HOTTZ; FERREIRA; VILARDI, 2018) analisa os resultados do desempenho dos alunos em Língua Portuguesa e Matemática no Sistema de Avaliação da Educação do Estado do Rio de Janeiro (Saerj). Constata que, passados os primeiros dois anos da implementação de uma nova proposta curricular e organizacional para o Ensino Médio na EJA na rede estadual, a EJA foi estruturada em quatro módulos e denominada Nova EJA. E conclui que as mudanças não conseguiram "[...] apresentar diferença positiva relevante em relação aos resultados de concluintes da EJA em três fases semestrais" (HOTTZ; FERREIRA; VILARDI, 2018, p. 580).

Outro fator de relevância é que a maioria dos trabalhos mencionados (três entre quatro artigos) não toma o Ensino Médio na EJA como objeto de estudo. Fato que, mais uma vez, ratifica a posição secundária que essa modalidade assume no meio científico, ao ser trabalhada como um elemento que acompanha a análise sobre o ensino regular, e não, de forma autônoma, como uma questão de pesquisa.

\section{Proeja}

Dos 39 artigos restantes, 21 versam sobre o Proeja e 18 abordam a EJA/EM apenas como locus da pesquisa. Podemos perceber, com essa maior concentração dos trabalhos nesses dois últimos eixos, que o Ensino Médio na modalidade EJA não tem sido objeto de análise das pesquisas científicas. Entre os 21 trabalhos que abordam o Proeja, destacam-se os 8 artigos que dizem respeito à temática Implantação e implementação do Proeja, e 6 trabalhos relativos à temática Currículo integrado. Em contrapartida, constata-se uma menor produção relativa à temática Perfil dos estudantes, desistência e permanência, com 3 artigos, e às temáticas Formação docente e Temáticas diversas, com apenas 2 cada uma.

No que se refere à temática que concentrou um número maior de trabalhos, verificamos que dois artigos evidenciam algumas dificuldades, tratadas ora como contradições, ora como equívocos do processo de implementação e implantação desse programa. Principalmente no sentido da distorção do princípio norteador de promover uma elevação da escolaridade da classe trabalhadora, destacando também a importância dos mecanismos de financiamento para a consolidação e a sustentação do Proeja.

$\mathrm{O}$ artigo Educação Profissional Integrada ao Ensino Médio na modalidade de Educação de Jovens e Adultos: caminhos e contradições (VITÓRIA; NOGUEIRA, 2016) 
trata da implementação e da consolidação do Proeja. Descreve seu processo de criação e apresenta as principais dificuldades na implementação, como, por exemplo, a falta de docentes com experiência em EJA, de compreensão sobre o currículo integrado, etc. E conclui que, apesar das contradições, o Proeja é "[...] fruto de uma demanda de luta histórica e social da elevação da escolaridade dos trabalhadores" (VITÓRIA; NOGUEIRA, 2016, p. 109).

Já o artigo Proeja: entre desafios e possibilidades (MOURA; HENRIQUE, 2012) apresenta um duplo movimento. Por um lado, aborda a gênese e os dois primeiros anos do Proeja, enfocando suas possibilidades de contribuir para a melhoria da EJA. Por outro, analisa as limitações e os equívocos inerentes à implementação do programa e avalia os ajustes realizados ao longo do processo para minorar seus limites. Discute desafios e possibilidades de o Proeja se tornar uma política pública educacional com interação nas redes públicas.

Os outros dois artigos abordam algumas políticas de educação profissional, entre as quais o Proeja. Gestão e avaliação das políticas públicas para Educação Profissional articulada ao Ensino Médio (2000-2010) (LIMA; SILVA; AZEVEDO, 2015) discute como determinadas políticas de Educação Profissional têm sido avaliadas (ou não avaliadas) pelos programas do Governo Federal: Brasil Profissionalizado, Proeja e Ensino Médio Inovador. E defende que tais políticas deveriam prever "[...] de que forma serão monitoradas e avaliadas para que depois de implantadas possam ser avaliadas e redefinidas, se necessário" (LIMA; SILVA; AZEVEDO, 2015, p. 110).

Já A política de educação profissional no Governo Lula: um percurso histórico controvertido (FRIGOTTO; CIAVATTA; RAMOS, 2005) analisa essas políticas considerando as principais contradições entre as propostas de governo do ex-presidente e suas ações. E faz um balanço da política de Educação Profissional construída após a LDB/1996 (BRASIL, 1996) até a primeira gestão do governo Lula. O texto analisa as disputas e os retrocessos no plano legislativo e nas políticas de educação profissional implementados de 1996 a 2005, demonstrando como elas têm sido voltadas para a formação do trabalho simples. Destaca os conflitos e as contradições ocorridos na disputa pela hegemonia pela formação do trabalhador. E conclui que a política tem sido realizada mediante programas de educação profissional, em sua maioria, focais e contingentes.

Seguindo a análise das outras quatro produções dessa temática, verificamos o artigo $O$ Programa de Integração da Educação Profissional com a Educação Básica na modalidade de Educação de Jovens e Adultos (Proeja) no IFG - Campus Goiânia: um percurso contraditório na construção do direito à educação (VITORETTE; CASTRO, 2016). Em análise da implantação e da implementação do Proeja no Instituto Federal de Goiás (IFG), as autoras constataram: apesar de questionamentos e contradições que revelaram posições 
conservadoras, a inclusão do Proeja no instituto "[...] permitiu a problematização dessas mesmas posturas e a oxigenação do debate interno" (VITORETTE; CASTRO, 2016, p. 308).

No artigo seguinte, Uma década do Proeja: sua gênese, balanço e perspectivas, Oliveira e Scopel (2016) desenvolvem um estudo sobre o percurso do Proeja durante a última década, empreendendo uma análise crítica e ampla sobre as implicações do Decreto $\mathrm{n}^{\mathrm{o}} 5.154$, de 23 de julho de 2004 (BRASIL, 2004), na formulação desse programa. Ademais, os autores apontam para os desafios de implementação do Proeja nos Institutos Federais, tendo em vista os grandes conflitos políticos e epistemológicos inerentes à proposta. Por fim, constatam que o Proeja ainda não se consolidou como política pública sob a perspectiva institucional.

No artigo Avaliação ex post da política pública Proeja no IFBA Campus Santo Amaro (BA), Flores (2017) investiga o cumprimento dos objetivos do Proeja enquanto política pública implementada no Instituto Federal da Bahia (IFBA). Questiona como e se ocorre a inclusão do público da EJA em termos de acesso, permanência e conclusão, a fim de contribuir para sua inserção no mundo do trabalho. E conclui que "[...] tal como vem sendo executada, não combate a exclusão, antes a perpetua, [...] ela se torna contraditória por ser uma política pretensamente inclusiva e que finda por ser excludente no que tange ao público da EJA" (FLORES, 2017, p. 88).

Por fim, o artigo Considerações sobre trabalho e Proeja no contexto de documentos legais (LAFFIN; VON MECHELN, 2016) aborda as contradições existentes entre a teoria (lei) e a prática (cotidiano das instituições), uma vez que tal discrepância evidencia descaso para com a EJA. A obra salienta que políticas públicas não são tratadas como tais, já que não são desenvolvidas nem efetivadas devidamente. Outro aspecto salientado é o fato de o processo formativo escolar ser distinto do processo formativo para o trabalho, haja vista que a diferença do ensino destinado para determinadas classes reforça a ideia de dualidade estrutural.

Em relação às produções sistematizadas na temática Perfil dos Estudantes, desistência e permanência, verificamos que o primeiro artigo que a contempla, Desistência $e$ permanência de estudantes de Ensino Médio do Proeja (FARIA; MOURA, 2015), investiga as razões pelas quais jovens e adultos são levados a abandonar a escola, bem como os motivos que fazem com que eles permaneçam nela. Assim, tendo como recorte de análise a desistência e a permanência dos estudantes do curso técnico de Eletrotécnica integrado ao Ensino Médio do Proeja no Instituto Federal do Rio Grande do Norte (IFRN), verifica que os fatores que propulsionam essas tomadas de decisões pelos alunos “[...] têm sua origem nas inter-relações entre aspectos institucionais, socioeconômicos e pessoais" (FARIA; MOURA, 2015, p. 151). 
E conclui que o Proeja não tem contribuído para assegurar a permanência de grande parte da classe trabalhadora que carece do direito à educação, reforçando, portanto, o aspecto dual da educação brasileira.

$\mathrm{O}$ artigo Perfil de estudantes do Proeja Técnico em Comércio do Instituto Federal Farroupilha (BEZERRA et al., 2015) analisa o perfil dos alunos do Proeja através do levantamento de aspectos socioeconômicos, institucionais e pessoais. Os autores constatam que a taxa de evasão escolar ocorre em maior parte entre os alunos mais jovens. E discutem algumas causas para a desistência. $\mathrm{Na}$ conclusão, destacam a necessidade de investir na formação docente para o ensino no Proeja, a fim de assegurar a permanência dos estudantes.

O terceiro artigo dessa temática, $O$ reencontro dos sujeitos com a escola: significados e tensões no âmbito do Proeja (SILVA; JORGE, 2018), investiga a problemática da desistência escolar no Ensino Médio noturno. Traça um perfil dos alunos do Proeja de 18 escolas estaduais de Curitiba, identificando os sentidos e os significados da experiência escolar para esses alunos e verificando se havia ou não uma relação entre o quadro identificado e os motivos para permanecerem ou desistirem da escola.

Os textos sobre Currículo Integrado destacam que o desafio maior é a integração curricular no Proeja, para que ele supere a dicotomia entre formação profissional e básica, destacando ser necessário respeitar a relação entre conhecimentos gerais e específicos. No artigo A avaliação do currículo do Ensino Médio Integrado no Proeja: um diálogo com Cronbach (ARAÚJO; HOLANDA, 2012), os autores, baseando-se em Joseph Lee Cronbach, comprometem-se a avaliar a proposta de currículo do Proeja, tendo em vista sua normatização. A partir de um levantamento bibliográfico e apoiando-se em autores que estudam a formação profissional, abordam de que maneira, mesmo em uma proposta de currículo integrado, ainda persiste a dicotomia entre Educação Básica e formação profissional.

Assim, podemos averiguar que a concepção de currículo integrado não poderá ser realizada plenamente sem que proporcione a união entre desenvolvimento social e econômico, de forma que possamos superar a dicotomia entre pensar e fazer. Articulando-se a essa reflexão, o artigo A política de integração curricular no âmbito do Proeja: entre discursos, sujeitos e práticas (SILVA, 2011) investigou como se dá a construção da proposta curricular, tendo como base de pesquisa os olhares dos sujeitos-autores do planejamento e a interpretação deles sobre a compreensão do trabalho como princípio educativo.

$\mathrm{O}$ artigo Produção artística digital colaborativa e aprendizagem curricular no projeto Proeja-Transiarte (TELES, 2014) discorre sobre novas formas de manifestações artísticas digitais como inovação pedagógica na EJA. A publicação objetiva evidenciar como 
ressignificar expressões artísticas já existentes, a fim de que, ao explorar a Transiarte, possibilitem a articulação da EJA com a Educação Profissional.

O projeto integrador e a centralidade do trabalho para a formação humana no programa de integração da educação profissional com a educação básica na modalidade de educação de jovens e adultos (Proeja) (ZEN; OLIVEIRA, 2014) traz uma análise sobre o conceito ontológico do trabalho, refletindo sobre a sua centralidade como princípio educativo na formação humana. Recupera o conceito amplo de trabalho e advoga sua centralidade no âmbito do Proeja, em especial na proposta de Projeto Integrador do Campus Vitória. Apresenta uma reflexão sobre a noção que os discentes têm do trabalho e propõe repensar a forma de organização curricular do Proeja, primando pela autonomia intelectual e pela ética dos alunos, a fim de resgatar a centralidade do trabalho no currículo do programa.

No artigo Os alunos do Proeja no IFRN Campus Currais Novos como usuários do serviço de empréstimo da biblioteca (SILVA; FARIAS, 2010), o foco é a utilização da biblioteca pelos alunos do programa, tendo como análise o serviço de empréstimo por temática de leitura. Dessa forma, o texto repensa a importância da utilização desses recursos pelos estudantes da modalidade supracitada. Frisa que a inexistência de bibliotecas é recorrente na realidade desses alunos e que outros recursos pedagógicos são limitados para os estudantes da EJA. Identifica o perfil do aluno que acessa esse serviço de empréstimo, apresentando uma análise de como as bibliotecas são utilizadas e como os conhecimentos adquiridos com esse contato trazem impactos para ao desenvolvimento do usuário. E endossa a concepção de que a EJA deve ser encarada como um direito.

Por conseguinte, no texto Histórias em Quadrinhos na Educação Artística, Energética e Ambiental no Proeja (FERRAREZ; SOUZA, 2017), o cerne da problemática baseia-se na utilização de meios pedagógicos alternativos e suas possibilidades; neste caso, as Histórias em Quadrinhos (HQs), destacando a importância da interdisciplinaridade e de um trabalho diferenciado no Proeja.

Verificamos que os dois textos relativos à temática Formação Docente consideram necessária uma política de formação docente específica para a modalidade EJA e apontam os desafios decorrentes de sua implementação. No artigo Compreensões sobre formação docente no âmbito do Proeja, Soares (2015, p. 33619) destaca que a "[...] formação docente para o Proeja é ainda uma realidade distante [...]" e expõe os resultados da pesquisa feita com docentes do IFG - Campus Luziânia, ressaltando que as formações são esporádicas e que os professores desconhecem a existência de uma política de formação docente na proposta do Proeja. 
Em O Proeja integrado à Educação Profissional: desafios, possibilidades e práticas docentes, Faria e Assis (2014) enfatizam a necessidade de um compromisso, por parte das entidades públicas integrantes dos sistemas educacionais, de investir no trabalho docente para a atuação na EJA a partir do ponto de vista dos estudantes do curso de Eletrotécnica do IFRN - Campus Caicó e destacam a ausência de formação docente para atuar no Proeja.

Finalmente, no que diz respeito às Temáticas Diversas, encontramos apenas duas produções que abordam assuntos outros. Ambas em nada se relacionam com as temáticas supracitadas - nem mesmo entre si -, mas tomam o Proeja como pano de fundo. Uma delas é o artigo Percepção ambiental dos estudantes do curso Técnico em Alimentos do Proeja no IFRN - Campus Currais Novos. Nele, Medeiros e Tabosa (2010) investigam a percepção ambiental dos alunos do curso de Técnico em Alimentos na modalidade de EJA ofertado no IFRN - Campus Currais Novos, a fim de analisar como tem ocorrido o processo formativo desses alunos no que tange ao seu comprometimento com o meio ambiente. Concluem que “[...] os alunos do Proeja possuem [...] conhecimentos intuitivos, adquiridos pela vivência, pela cultura e senso comum, acerca das questões ambientais" (MEDEIROS; TABOSA, 2010, p. 192-193).

O outro artigo presente nessa temática, Atitudes e crenças sobre as relações CTSA [Ciência, Tecnologia, Sociedade e Ambiente] de estudantes do curso de Edificações na modalidade EJA: uma análise por períodos (NUNES et al., 2010), tem como foco a percepção dos alunos do instituto (estudantes do Proeja) sobre o binômio ciência e tecnologia. Ainda assim, investiga a concepção de 'alfabetização científica', para entender a relação dos meios tecnológicos com a sustentabilidade.

\section{EJA/EM como locus da pesquisa}

Quanto às produções do Eixo 3, que abordam o Ensino Médio na EJA apenas como locus de suas pesquisas, constatamos uma pluralidade de temáticas. E justamente por terem em comum apenas esse aspecto relativo ao locus da investigação é que não foi possível sistematizar a maioria dos artigos encontrados em temáticas específicas. Dos 18 artigos que compõem esse eixo, apenas 3 foram concentrados na temática Relação Trabalho-Educação. E os outros 15, por tratarem de temas variados, foram agrupados em uma mesma temática, denominada Temáticas Diversas, a qual concentra, especificamente, 10 artigos e ainda agrega duas subtemáticas: Educação Básica, com três análises relacionadas ao percurso escolar dos estudantes; e Educação Especial, com dois estudos abordando esse tema específico na modalidade EJA. 
No que tange à temática Relação Trabalho-Educação, evidenciam-se diferentes tipos de abordagens. O primeiro artigo, A relação trabalho e educação e suas implicações na Educação de Jovens e Adultos (FERREIRA; PEREIRA, 2018), apresenta a necessidade de um enfrentamento da lógica do mercado de trabalho, ressaltando a importância de uma formação integral dos alunos da EJA que compreenda o trabalho como princípio educativo. Evidencia a necessidade de se reconhecer a EJA como uma ferramenta de enfrentamento das desigualdades sociais que precisa ser realizada como uma política pública educacional, e não como um conjunto de projetos fragmentados.

O segundo artigo desse primeiro eixo, Educação e trabalho: representações de professores e alunos do Ensino Médio (GOMES et al., 2006), compara a relação que os alunos da EJA e do Ensino Médio regular têm com o mundo do trabalho. Constatando que, para os primeiros, o trabalho é um fator que, ao mesmo tempo, retira-os da escola e os faz retornar a ela - devido às exigências do mercado -, ao passo que, para os outros, o trabalho ainda é uma realidade distante, tendo em vista o fato de esses sujeitos estarem supostamente destinados à educação superior. O que evidencia a presença de uma dualidade estrutural.

Esse texto, assim como o primeiro, busca entender as percepções de alunos e professores sobre o binômio trabalho-educação, analisando suas perspectivas e seus desdobramentos. Possui como linha de investigação a história da educação, envolvendo também o recorte da classe à que essa discussão se encaminha. Assim, os impactos da ordem econômica e social vigente no aparelho escolar são postos em evidência, uma vez que a visão da educação como investimento e mercadoria serve como pano de fundo para entender as relações sociais.

Por fim, com um caráter menos crítico, o artigo Qualidade de vida no trabalho: uma percepção de trabalhadores que retornaram ao ensino formal (ANDRADE, A. et al., 2006) identifica uma melhora da qualidade de vida no trabalho de sujeitos que voltaram a estudar devido às exigências de qualificação do mercado de trabalho. Mostra que o processo de escolarização acarretou aspectos positivos na vida social e profissional dos trabalhadores entrevistados. E conclui, de forma pouco crítica, que é "[...] importante que as empresas invistam na qualificação de seus funcionários [...], pois acredita-se que tanto o trabalhador como as empresas serão beneficiadas" (ANDRADE, A. et al., 2006, p. 411).

No que diz respeito às Temáticas Diversas, constatamos uma variedade de estudos que tratam de temas, que vão desde uma análise do processo de reescrita até as investigações que pretendiam avaliar o conhecimento que algumas alunas da EJA possuíam sobre o exame de mama enquanto fator de prevenção do câncer de mama. Nesse sentido, o primeiro artigo dessa 
seção, A possibilidade de produção de saberes docentes na EJA/RS: rascunhos e desenhos (SOARES; LOGUERCIO; FERREIRA, 2011), discute a formação em serviço que havia para os professores da EJA de Ensino Médio no Rio Grande do Sul e a possibilidade de construção de um saber coletivo próprio à docência na EJA.

Os autores concluem que existem saberes próprios à EJA. Saberes que, apesar das dificuldades, estavam sendo constituídos in loco, nos espaços de formação em serviço, nos embates de teoria e prática realizados pelos professores, "[...] constituindo assim o que chamamos de Saber da EJA" (SOARES; LOGUERCIO; FERREIRA, 2011, p. 15-16).

Na sequência, o artigo Políticas Educacionais: aproximações entre Ensino Médio, EJA e Educação Profissional (SILVA et al., 2017) objetiva apreender as tendências e as convergências entre as pesquisas sobre políticas educacionais. Expõe as possíveis articulações entre os trabalhos acerca do Ensino Médio, da EJA e da Educação Profissional nas produções científicas apresentadas no II Seminário da Associação Nacional de Política e Administração da Educação (Anpae) - Região Sul. Trata-se de uma pesquisa qualitativa, de cunho bibliográfico, a partir dos Anais do evento. Que aborda, primeiramente, a importância das pesquisas sobre as políticas educacionais no contexto atual. Depois, as temáticas tratadas nas produções e as tendências e convergências das políticas educacionais analisadas.

Já no artigo A reescrita como processo: as vantagens de uma segunda versão tardia, Sartori e Mendes (2006) analisam duas versões de textos produzidos por alunos da EJA de Ensino Médio. Defendem a reescrita como etapa fundamental do processo de escrita e discutem as vantagens de uma segunda versão tardia em propiciar mudanças qualitativas nas primeiras versões entregues. Mostram, assim, que a distância temporal é um fator positivo para a escrita, porque proporciona tempo ao autor/aluno para se apropriar de novos ou de outros conhecimentos e melhorar significativamente a sua escrita. Quanto ao aspecto teóricometodológico, o artigo diz-se oriundo de uma pesquisa qualitativa, no âmbito de uma pesquisa-ação, embasada na concepção de dialogismo do Círculo de Bakhtin.

Outro artigo localizado foi $O$ Ensino Médio ministrado no Centro Educacional Patativa Assaré (FIALHO, 2012), que discute como jovens em conflito com a lei concebem a experiência da escolarização estando internados em instituições socioeducativas. $\mathrm{O}$ autor entrevistou sete jovens do Centro Educacional Patativa do Assaré (Cepa) enquanto cumpriam medida socioeducativa de privação de liberdade. Numa abordagem qualitativa, foram ouvidas suas histórias de vida e feita uma pesquisa bibliográfica e documental. Nos resultados e discussões sobre a educação escolar no Cepa, as maiores queixas dos alunos eram sobre o curto tempo em sala de aula, a ausência da disciplina Educação Física, a falta de informática e a impossibilidade de ler livros nos dormitórios. 
Conclui-se, portanto, que o modo com que a educação escolar é ministrada não contempla sua finalidade legal de desenvolver o educando para o exercício da cidadania e para a progressão em estudos posteriores, caracterizando-se pela precária qualidade do que é proposto.

$\mathrm{O}$ artigo Percepção ambiental do corpo docente e discente da modalidade EJA de uma escola estadual no município de Pombal-PB (ANDRADE, S. et al., 2016) objetivou investigar o nível de percepção ambiental dos docentes e discentes da EJA de Ensino Médio. Foram aplicados questionários a 23 alunos e 7 professores e feita a análise dos recursos didáticos que a escola oferece. Os resultados indicaram que os alunos tinham boa noção do conceito de meio ambiente e dos seus elementos. Os professores destacaram a importância do financiamento para se trabalhar melhor com a temática ambiental na EJA.

Por fim, Juventudes na Educação de Jovens e Adultos: contradições entre suas conquistas como sujeitos de direitos e os silenciamentos nos espaços escolares (SOUZA; REIS, 2017) analisa os relatos de três jovens alunos da EJA de uma escola estadual de Ensino Médio, “[...] procurando refletir sobre os silenciamentos que permeiam a relação desses/as jovens com sua própria condição juvenil e com a escola [...]” (SOUZA; REIS, 2017, p. 99). E conclui que, para que a modalidade atenda à juvenilização do seu público, será preciso “[...] ver o/a aluno/a jovem da EJA como, antes de tudo ‘jovem', e não apenas como uma categoria 'aluno"' (SOUZA; REIS, 2017, p. 108), desconsiderando suas múltiplas identidades.

$\mathrm{O}$ artigo Competência em informação por estudantes de Ensino Médio (Educação de Jovens e Adultos) na cidade de Ribeirão Preto/SP (MANCERA; CASTRO FILHO, 2018) apresenta um estudo de caso único e de abordagem quanti-qualitativa, que investiga as competências relacionadas à busca e ao uso da informação por estudantes da EJA. Os resultados obtidos apontaram que, apesar de jovens e adultos possuírem aparente familiaridade com a internet, “[...] não conseguem satisfatoriamente organizar, analisar e documentar informações, assim como, têm necessidades de aperfeiçoamento em leitura e escrita" (MANCERA; CASTRO FILHO, 2018, p. 38). Os autores concluem afirmando a necessidade da inclusão transversal da Competência em Informação (CoInfo) na Educação.

$\mathrm{O}$ artigo Autoexame das mamas como fator de prevenção ao câncer: uma abordagem com estudantes de uma escola pública da cidade de São Francisco do Conde - Bahia (ALMEIDA et al., 2015) apresenta um estudo descritivo e quantitativo sobre o conhecimento que as alunas da EJA de uma escola pública de São Francisco do Conde possuem sobre a importância da realização desse exame como fator importante para prevenção do câncer. A partir dos questionários, os autores concluem que "[...] as estudantes do município de São 
Francisco do Conde necessitam de mais informações sobre prevenção ao câncer de mama, especialmente nos postos de atenção básica em saúde [...]” (ALMEIDA et al., 2015, p. 110).

$\mathrm{O}$ artigo Gênero textual exposição oral na Educação de Jovens e Adultos (BALTAR; COSTA, 2010) parte da problemática de o emprego dos gêneros textuais orais ser muito incipiente no cenário escolar. Os autores apresentam uma sequência didática para a aplicação do gênero exposição oral e relatam as experiências positivas obtidas em duas turmas da EJA de uma escola pública do município de Caxias do Sul. Destacam que, após a realização da sequência didática proposta, houve significativas melhorias na escrita e na fala dos alunos, bem como no que tange às interações sociais dentro da sala de aula, uma vez que tal experiência ocasionou maior entrosamento e desinibição na turma e aumentou a autoestima dos alunos.

Por fim, a partir de uma análise de menor abrangência, o artigo intitulado Motivos de evasão e retorno de jovens e adultos ao Ensino Médio em Alegre-ES (CASSAMALI et al., 2016) investiga os principais motivos de evasão e retorno entre os alunos da EJA. E constata que a principal causa relativa ao abandono da escola se dá em função da necessidade de trabalhar para contribuir com a renda familiar e, por outro lado, que o desejo de conseguir um emprego melhor constitui-se em um grande fator para que jovens e adultos voltem a estudar.

Ainda dentro de Temáticas Diversas, houve a necessidade de criar subtemáticas, a fim de comportar um conjunto de textos que se diferenciavam dos demais, por trazerem alguns aspectos em específico. No primeiro caso, a subtemática intitulada Educação Básica (Ensino Fundamental e Ensino Médio), reúne três textos, cuja amostra considera, além de alunos do Ensino Médio na EJA, alguns alunos do Ensino Fundamental.

No artigo Trajetórias juvenis de mulheres em privação de liberdade e experiências escolares: os sentidos produzidos nos encontros e desencontros com a escola (SANTOS, 2015), a partir de uma coleta de dados - análises documentais, observações, questionários e entrevistas -, a autora procurou analisar a trajetória que cada mulher percorreu até ali. Realizada em um complexo penitenciário de Santa Catarina, a pesquisa mostrou que, embora a escola, no contexto atual de suas vidas, não fosse vista com grande importância, antes da privação de suas liberdades, era considerada um lugar marcante para elas. Alguns relatos mostraram como as instituições escolares, ainda que não abraçassem suas demandas, tornando-se desinteressantes e indiferentes, eram reconhecidas como espaço essencial para a troca de saberes, aprendizagem e socialização.

No artigo Educação de Jovens e Adultos: o retorno das mulheres à escola, Rieger e Alexandre (2011) investigam as ações que determinadas mulheres empreendem em suas vidas a fim de construírem condições que as permitam retornar à escola. Compreendem que esse 
processo não consiste apenas em uma simples tomada de decisão de voltar a estudar, pois envolve também um esforço de reorganização para conciliar os estudos com o trabalho e a família. Os autores constatam que, retornando à escola, as mulheres se tornam "[...] mais preparadas e confiantes, deixam o medo de lado e são capazes de exprimir os seus pensamentos, as suas vivências e as experiências acumuladas durante seu longo período de vida" (RIEGER; ALEXANDRE, 2011, p. 169).

$\mathrm{O}$ artigo Trajetórias truncadas, trabalho de futuro: jovens fora de série na escola pública de Ensino Médio analisa a trajetória de jovens e adultos, constatando que há “[...] uma superposição entre os tempos de trabalho e escola [...]" (CARRANO; MARINHO; OLIVEIRA, 2015, p. 1439). E conclui que o trabalho congrega um aspecto duplo na vida desses sujeitos, isto é, do mesmo modo que representa um obstáculo à continuidade dos estudos, quando aliado à tarefa de estudar, pode significar também independência e/ou autonomia. Para endossar esse viés, são apresentados dados do Ensino Fundamental e do Ensino Médio.

Tratando da segunda e última subtemática, Educação Especial, esta congrega, como o próprio nome diz, estudos que tratam de experiências e trajetórias de alunos com necessidades educacionais especiais na EJA. Assim, a partir de uma pesquisa realizada com quatro alunos em uma escola pública do Noroeste do Paraná, o artigo $O$ trabalho com o gênero textual História em Quadrinhos com alunos que possuem deficiência intelectual (SHIMAZAKI et al., 2018) investiga o modo como se desenvolvem os conceitos científicos presentes nas Histórias em Quadrinhos (HQs), a fim de que pessoas com Deficiência Intelectual (DI) consigam apreendê-los.

O texto se constrói a partir da ideia de buscar alternativas para que estudantes com DI possam se apropriar de conhecimentos culturais e sociais a partir da análise e da construção de sua própria HQ. Por fim, foi possível perceber que, apesar de a alternativa para a apropriação de conhecimentos ser acessível e necessária, os sujeitos da pesquisa ainda demonstram grandes dificuldades para entender o tema, a finalidade e o clímax das histórias.

O segundo artigo dessa subtemática, intitulado Percurso escolar de estudantes com deficiência na Educação de Jovens e Adultos, nível Ensino Médio (LEITE; CAMPOS, 2018), apresenta uma pesquisa de abordagem qualitativa sobre a trajetória escolar de dez alunos com deficiência do Ensino Médio da EJA de variadas escolas regulares do interior de São Paulo. Segundo as autoras, a EJA se torna uma oportunidade de inserção social para esses alunos. No entanto, a falta de acessibilidade quanto aos recursos pedagógicos e à estrutura física da escola também são dificuldades presentes nos relatos dos alunos sobre a experiência nessa 
modalidade. Elas concluem afirmando "[...] a importância de as escolas reconhecerem as necessidades individuais de seus educandos” (LEITE; CAMPOS, 2018, p. 30).

\section{Considerações Finais}

Mediante os resultados obtidos no levantamento, pudemos verificar que, a despeito de os trabalhos considerarem a Educação de Jovens e Adultos no Ensino Médio enquanto campo de investigação, nota-se que essa etapa da modalidade ainda não se configura, no meio acadêmico, como objeto principal de pesquisa, sendo abordada com maior frequência a partir da experiência de um programa federal ou como o local em que ocasionalmente a investigação possa vir a ser realizada. Dessa forma, não podemos negar que, de fato, haja bastante produção acerca da EJA, todavia, com relação à reflexão sobre propostas pedagógicas próprias para a modalidade no Ensino Médio, as produções tornam-se escassas.

Quanto aos trabalhos localizados, chamam-nos a atenção três aspectos em específico: a) a grande abordagem do Proeja; b) um fenômeno de secundarização da EJA de nível médio; e c) a EJA de nível médio como elemento de complementação das análises feitas sobre o Ensino Médio regular. O primeiro diz respeito à grande quantidade de trabalhos sobre a EJA/EM que tinham como foco o Proeja, correspondendo precisamente à metade dos artigos levantados. Esse dado é compreensível considerando a relevância e a metodologia do programa. Apesar de o Proeja ser pequeno quantitativamente, mobilizou muitas pesquisas dedicadas a ele. No entanto, e não é nossa intenção condenar tais trabalhos, é preciso atentar para o fato de que a Educação de Jovens e Adultos de nível médio não se resume apenas ao Proeja. Esse programa se constitui em uma das facetas da EJA/EM, mas não é a única.

Aliado a isso, destaca-se que, embora boa parte dos artigos relativos a esse programa investigue um aspecto específico dentro de um determinado Instituto Federal (IF), são trabalhos que, em sua maioria, elaboram uma articulação entre aspectos micro e macrossociais. Consistem, geralmente, em investigações que assumem uma perspectiva crítica diante da análise do objeto pesquisado e se preocupam em inseri-lo historicamente no contexto em que estão sendo consideradas. A partir do fato de a EJA, com recorrência, ser tratada como (sub)modalidade da educação, com ações governamentais direcionadas a campanhas, programas e projetos, e não como política pública de fato, questionamos: seria a EJA/EM um (sub)tema de pesquisa na academia, reduzido a programas (no caso em questão, ao Proeja), tal como na esfera político-educacional?

Aqui, abrimos espaço para a discussão sobre o lugar que a EJA de nível médio ocupa na academia. Infelizmente, a secundarização da EJA enquanto modalidade de ensino é um dado de sua trajetória que ainda a afeta na atualidade. Com isso, o não reconhecimento da 
EJA como área específica e a invisibilidade característica dessa modalidade de ensino são reiterados no campo teórico das produções acadêmicas, principalmente se o foco for a etapa final da Educação Básica, ou seja, a EJA/EM quase inexiste enquanto objeto de pesquisa. Tal afirmação é comprovada pela grande quantidade de trabalhos nos quais a EJA/EM constitui apenas o locus da pesquisa. Que analisam, portanto, dentro do contexto da EJA/EM, aspectos outros que não a política pública de fato voltada a essa temática.

O caráter secundário da EJA pode ser confirmado a partir da constatação de que o eixo EJA/EM como locus da pesquisa, contando com o total de 18 trabalhos, representa uma parcela significativa dentro de um conjunto de 43 artigos. Destaca-se, nesse eixo, uma diversidade de temáticas. De modo que a maioria das produções se dedica a investigar uma questão específica de uma determinada experiência de EJA/EM, a partir de pontos de vista que ora assumem uma postura crítica, ora se configuram de uma maneira não muito clara.

Por outro lado, constatamos que, quando não abordada de forma majoritária pelo Proeja ou como locus de pesquisa, a EJA/EM é apresentada com a finalidade de trazer dados que complementam fenômenos verificados no ensino regular ou de tornar mais completa a investigação realizada acerca do Ensino Médio como um todo. Essa observação é representada pelos três artigos alocados no eixo temático Ensino médio na modalidade EJA.

Assim, é possível dizer que as produções encontradas não tinham como objetivo principal investigar e analisar a EJA/EM como objeto em si, o que atesta a falta de protagonismo conferida à Educação de Jovens e Adultos no meio científico. Acrescenta-se a isso a percepção de que, embora se trate de investigações relativas ao Ensino Médio, nenhuma delas se deteve à análise de uma Secretaria Estadual de Educação, e foram raras as pesquisas que citaram esse órgão administrativo, responsável por essa etapa de ensino.

$\mathrm{O}$ artigo sobre a EJA no Rio de Janeiro destaca que, apesar de situar o novo modelo para o Ensino Médio, adotado a partir de 2012 pela Secretaria de Estado de Educação (Seeduc-RJ), tal iniciativa apresenta uma perspectiva de aferir índices, taxas, resultados de proficiência da EJA em módulos sem que se discuta de maneira qualitativa e aprofundada essa política educacional e sua concepção. Assim, é de causar espanto a escassez de análises de propostas curriculares para a EJA/EM no âmbito das secretarias estaduais de educação.

Por fim, salientamos que, embora os artigos não tenham correspondido a nossas expectativas de encontrar trabalhos que tratassem sobre o Ensino Médio na modalidade EJA, de uma maneira geral, os trabalhos se posicionaram de forma crítica a respeito do tema por eles pesquisado. Diante do exposto, as constatações aqui levantadas nos levam a crer que há uma lacuna acadêmica com relação à temática desta pesquisa, ao mesmo tempo em que nos 
levam a questionar o motivo da escassez de trabalhos acerca desse tema. Essa situação é tão intrigante quanto preocupante. E reflete, de certa maneira, a posição que a EJA ocupa no cenário das políticas educacionais.

Assim sendo, esta pesquisa bibliográfica nos permitiu esboçar um panorama, mesmo que sucinto, do que se tem pesquisado sobre o Ensino Médio na EJA e, de uma maneira geral, constatamos que esse ainda é um tema pouco abordado na literatura acadêmica. Em suma, esta parece ainda desconhecer a EJA/EM ou pelo menos a aborda apenas em partes. Faz-se necessário, então, apreendê-la por completo através de uma perspectiva científica e crítica, a fim de que se possa pôr em evidência sua realidade e seus desafios, bem como para que seja possível fomentar reflexões acerca de sua importância social. Esse movimento é necessário para que avancemos de maneira mais significativa nessa área de estudo, demarcando o escopo acadêmico também como espaço de luta, ao evidenciar, em sua integralidade, a importância da modalidade aqui investigada.

\section{Referências}

ALMEIDA, M. S. P. de et al. Autoexame das mamas como fator de prevenção ao câncer: uma abordagem com estudantes de uma escola pública da cidade de São Francisco do Conde - Bahia. RevInter, [S. l.], v. 8, n. 1, p. 100-112, fev. 2015. DOI: https://doi.org/10.22280/revintervol8ed1.196. Disponível em: https://bit.ly/2SFSEmJ. Acesso em: 26 jun. 2019.

ANDRADE, A. et al. Qualidade de vida no trabalho: uma percepção de trabalhadores que retornaram ao ensino formal. Educação, Santa Maria, v. 31, n. 2, p. 403-412, jul./dez. 2006. DOI: http://dx.doi.org/10.18378/rvads.v11i1.3974. Disponível em: https://bit.ly/31RatTR. Acesso em: 5 dez. 2018.

ANDRADE, S. O. de et al. Percepção ambiental do corpo docente e discente da modalidade EJA de uma escola estadual no município de Pombal-PB. Revista Verde de Agroecologia e Desenvolvimento Sustentável, Pombal, v. 11, n. 1, p. 1-9, 2016. Disponível em: https://bit.ly/2SmCiR0. Acesso em: 5 dez. 2018.

ARAÚJO, A. C. U.; HOLANDA, P. H. C. A Avaliação do currículo do Ensino Médio integrado no Proeja: um diálogo com Cronbach. Revista Espaço do Currículo, [S. l.], v. 4, n. 2, p. 322-336, mar. 2012. Disponível em: https://bit.ly/2HiU4hx. Acesso em: 26 jun. 2019.

BALTAR, M. A. R.; COSTA, D. R. da. Gênero textual exposição oral na Educação de Jovens e Adultos. Revista Brasileira de Linguística Aplicada, Belo Horizonte, v. 10, n. 2, 2010. DOI: http://dx.doi.org/10.1590/S1984-63982010000200006 Disponível em: https://bit.ly/2SJuV50. Acesso em: 5 dez. 2018.

BEZERRA, A. S. et al. Perfil de estudantes do Proeja Técnico em Comércio do Instituto Federal Farroupilha - município de Júlio de Castilhos/RS em 2012. Regae - Revista de Gestão e Avaliação Educacional, Santa Maria, p. 41-50, abr. 2015. e-ISSN 2318-1338. DOI: http://dx.doi.org/10.5902/2318133817060. Disponível em: https://bit.ly/39xGuD4. Acesso em: 9 nov. 2018.

BRASIL. Lei no 9.394, de 20 de dezembro de 1996. Diário Oficial da União: Brasília, DF, Seção 1, p. 27833, 23 dez. 1996. Estabelece as diretrizes e bases da educação nacional. Disponível em: 
https://bit.ly/37qvOVA. Acesso em: 9 nov. 2015. Disponível em: https://bit.ly/37m4dof. Acesso em: 24 jun. 2019.

BRASIL. Ministério da Educação. Parecer CNE/CEB n ${ }^{\circ} 11$, de 10 de maio de 2000. Diretrizes Curriculares Nacionais para a Educação de Jovens e Adultos. Diário Oficial da União: Brasília, DF, Seção 1e, p. 15, 9 jun. 2000. Disponível em: https://bit.ly/37lusLD. Acesso em: 9 nov. 2018.

BRASIL. Decreto ${ }^{0} 5.154$, de 23 de julho de 2004. Diário Oficial da União: Brasília, DF, Seção 1, p. 18, 26 jul. 2004. Regulamenta o $\S 2^{\circ}$ do art. 36 e os arts. 39 a 41 da Lei $n^{\circ} 9.394$, de 20 de dezembro de 1996, que estabelece as diretrizes e bases da educação nacional, e dá outras providências. Disponível em: https://bit.ly/37qvOVA. Acesso em: 9 nov. 2015.

BRASIL. Emenda Constitucional $n^{\circ} 59$, de 11 de novembro de 2009. Acrescenta $\S 3^{\circ}$ ao art. 76 do Ato das Disposições Constitucionais Transitórias para reduzir, anualmente, a partir do exercício de 2009, o percentual da Desvinculação das Receitas da União incidente sobre os recursos destinados à manutenção e desenvolvimento do ensino de que trata o art. 212 da Constituição Federal, dá nova redação aos incisos I e VII do art. 208, de forma a prever a obrigatoriedade do ensino de quatro a dezessete anos e ampliar a abrangência dos programas suplementares para todas as etapas da educação básica, e dá nova redação ao $\S 4^{\circ}$ do art. 211 e ao $\S 3^{\circ}$ do art. 212 e ao caput do art. 214, com a inserção neste dispositivo de inciso VI. Diário Oficial da União: Brasília, DF, Seção 1, p. 8, 12 nov. 2009. Disponível em: https://bit.ly/37qvOVA. Acesso em: 9 nov. 2015. Disponível em: https://bit.ly/2w76RkT. Acesso em: 24 jun. 2019.

BRASIL. Secretaria de Estado da Educação do Paraná. Educação Profissional Integrada à Educação de Jovens e Adultos. Curitiba: SEED - PR, 2010. Disponível em: $<$ http://www.educadores.diaadia.pr.gov.br/arquivos/File/diretrizes/diretriz_proeja.pdf $>$. Acesso em: 9 nov. 2018.

BRASIL. Lei $\mathrm{n}^{\circ}$ 13.415, de 16 de fevereiro de 2017. Altera as Leis $\mathrm{n}^{\circ}$ 9.394, de 20 de dezembro de 1996, que estabelece as diretrizes e bases da educação nacional, e 11.494, de 20 de junho 2007, que regulamenta o Fundo de Manutenção e Desenvolvimento da Educação Básica e de Valorização dos Profissionais da Educação, a Consolidação das Leis do Trabalho - CLT, aprovada pelo Decreto-Lei ${ }^{\circ}$ 5.452, de $1^{\circ}$ de maio de 1943, e o Decreto-Lei $\mathrm{n}^{\circ} 236$, de 28 de fevereiro de 1967; revoga a Lei ${ }^{\circ}$ 11.161, de 5 de agosto de 2005; e institui a Política de Fomento à Implementação de Escolas de Ensino Médio em Tempo Integral. Diário Oficial da União: Brasília, DF, Seção 1, p. 1, 17 fev. 2017. Disponível em: https://bit.ly/37qvOVA. Acesso em: 9 nov. 2015. Disponível em: https://bit.ly/37m4dof. Acesso em: 24 jun. 2019.

CARRANO, P. C. R.; MARINHO, A. C.; OLIVEIRA, V. N. M. de. Trajetórias truncadas, trabalho de futuro: jovens fora de série na escola pública. Educação e Pesquisa, São Paulo, v. 41, p. 1439-1454, dez. 2015. Edição especial. ISSN 1678-4634. DOI: http://dx.doi.org/10.1590/S15179702201508143413. Disponível em: https://bit.ly/2HiYjcX. Acesso em: 5 dez. 2018.

CASSAMALI et al. Motivos de evasão e retorno de jovens e adultos ao Ensino Médio em Alegre-ES. In: ENCONTRO LATINO AMERICANO DE INICIAÇÃO CIENTÍFICA, 20. São José dos Campos, 2016. Anais [...]. São José dos Campos: Universidade do Vale do Paraíba, 2016. p. 1-6. Disponível em: https://bit.ly/37s8SoO. Acesso em: 5 dez. 2018.

FARIA, D. S. A.; ASSIS, S. M. O Proeja integrado à Educação Profissional: desafios, possibilidades e práticas docentes. HOLOS, $[S$. l. $]$, Ano 30, v. 2, p. 123-133, maio 2014. Disponível em: https://bit.ly/2vrxtNo. Acesso em: 9 nov. 2018.

FARIA, D. S. A.; MOURA, D. H. Desistência e permanência de estudantes de Ensino Médio do Proeja. HOLOS, [S. l.], Ano 31, v. 4, p. 151-165, ago. 2015. Disponível em: https://bit.ly/2SFVHv3. Acesso em: 9 nov. 2018. 
FERRAREZ, A. H.; SOUZA, A. C. Histórias em Quadrinhos na Educação Artística, Energética e Ambiental no Proeja. HOLOS, $[S . \quad$ l. $]$, v. 4, p. 201-216, set. 2017. DOI: https://doi.org/10.15628/holos.2017.5544. Disponível em: https://bit.ly/2ORsGf4. Acesso em: 9 nov. 2018.

FERREIRA, D. F.; PEREIRA, V. A. A relação trabalho e educação e suas implicações na Educação de Jovens e Adultos. RELACult, [S. l.], v. 4, fev. 2018. Edição especial. e-ISSN: 2525-7870. Disponível em: https://bit.ly/2HlhB1x. Acesso em: 5 dez. 2018.

FIALHO, L. M. F. O Ensino Médio ministrado no Centro Educacional Patativa do Assaré. HOLOS, Ano 28, v. 2, p. 184-192, maio 2012. DOI: https://doi.org/10.15628/holos.2012.870. Disponível em: $<$ http://www2.ifrn.edu.br/ojs/index.php/HOLOS/article/view/870/541 >. Acesso em: 5 dez. 2018.

FLORES, T. M. D. Avaliação ex post da política pública Proeja no IFBA Campus Santo Amaro (BA). HOLOS, [S. l.], Ano 33, v. 3, p. 75-89, set. 2017. DOI: https://doi.org/10.15628/holos.2017.5756. Disponível em: https://bit.ly/2HncM80. Acesso em: 9 nov. 2018.

FRIGOTTO, G.; CIAVATTA, M.; RAMOS, M. A política de educação profissional no Governo Lula: um percurso histórico controvertido. Educação e Sociedade, Campinas, v. 26, n. 92, p. 1087-1113, out. 2005. e-ISSN 1678-4626. DOI: http://dx.doi.org/10.1590/S0101-73302005000300017. Disponível em: https://bit.ly/2uItDzk. Acesso em: 9 nov. 2018.

GOMES, C. A.; CARNIELLI, B. L. Expansão do Ensino Médio: temores sobre a Educação de Jovens e Adultos. Cadernos de Pesquisa, São Paulo, n. 119, p. 47-69, jul. 2003. ISSN 0100-1574. DOI: http://dx.doi.org/10.1590/S0100-15742003000200003.

GOMES, C. A. et al. Educação e trabalho: representações de professores e alunos do Ensino Médio. Ensaio: avaliação e políticas públicas em Educação, Rio de Janeiro, v. 14, n. 50, p. 11-26, jan./mar. 2006. Disponível em: https://bit.ly/2SpNBbd. Acesso em: 5 dez. 2018.

HOTTZ, A. D.; FERREIRA, C. da S.; VILARDI, L. O. Um novo modelo de EJA para o Ensino Médio no Rio de Janeiro. Estudos em Avaliação Educacional, São Paulo, v. 29, n. 71, p. 554-582, maio/ago. 2018. Disponível em: https://bit.ly/38rbswy. Acesso em: 5 dez. 2018.

LAFFIN, M. H. L. F.; VON MECHELN, M. Z. Considerações sobre trabalho e Proeja no contexto de documentos legais. Poiésis - Revista do Programa de Pós-Graduação em Educação, Tubarão, v. 10, p. 151-168, nov. 2016. e-ISSN 2179-2534. DOI: http://dx.doi.org/10.19177/prppge.v10e02016151-168. Disponível em: https://bit.ly/38padOF. Acesso em: 9 nov. 2018.

LEITE, G. G.; CAMPOS, J. A. de P. P. Percurso escolar de estudantes com deficiência na educação de jovens e adultos, nível médio. Revista Brasileira de Educação Especial, Bauru, v. 24, n. 1, p. 17-32, jan./mar. 2018. e-ISSN 1980-5470. DOI: http://dx.doi.org/10.1590/s1413-65382418000100003. Disponível em: https://bit.ly/2uGpDPQ. Acesso em: 5 dez. 2018.

LIMA, E. R.; SILVA, L. L. S.; AZEVEDO, M. A. de. Gestão e avaliação das políticas públicas para educação profissional articulada ao Ensino Médio (2000-2010). Regae - Revista de Gestão e Avaliação Educacional, Santa Maria, v. 4, n. 7, p. 97-112, jan./jun. 2015. e-ISSN 2318-1338. DOI: http://dx.doi.org/10.5902/2176217115287. Disponível em: https://bit.ly/2UJAPWx. Acesso em: 9 nov. 2018.

MANCERA, M. G.; CASTRO FILHO, C. M. de. Competência em informação por estudantes de Ensino Médio (Educação de Jovens e Adultos) na cidade de Ribeirão Preto/SP. Páginas a\&b, [S. l.], Série 3, p. 30-45, 2018. Edição especial. DOI: 10.21747/21836671/pag2018a3. Disponível em: https://bit.ly/39t6Upv. Acesso em: 5 dez. 2018. 
MEDEIROS, L. C.; TABOSA, W. A. F. Percepção ambiental dos estudantes do Curso Técnico em Alimentos do Proeja no IFRN - Campus Currais Novos. HOLOS, [S. l.], Ano 26, v. 3, p. 178-195, set. 2010. Disponível em: https://bit.ly/3bwxP5K. Acesso em: 9 nov. 2018.

MORAES, C. S. V.; ALAVARSE, O. M. Ensino médio: possibilidades de avaliação. Educação e Sociedade, Campinas, v. 32 n. 116, p. 807-838, jul./set. 2011. ISSN 0101-7330. http://dx.doi.org/10.1590/S0101-73302011000300011. Disponível em: https://bit.ly/2ONMWy7. Acesso em: 20 set. 2018.

MOURA, D. H.; HENRIQUE, A. L. S. Proeja: entre desafios e possibilidades. HOLOS, [S. l.], Ano 28, v. 2, p. 114-129, maio 2012. Disponível em: https://bit.ly/2SIV2Qv. Acesso em: 9 nov. 2018.

NUNES, A. O. et al. Atitudes e crenças sobre as relações CTSA de estudantes do curso de Edificações na modalidade EJA: uma análise por períodos. HOLOS, [S. l.], Ano 26, v. 5, p. 244-254, 2010. DOI: https://doi.org/10.15628/holos.2010.577. Disponível em: https://bit.ly/2SJiYwp. Acesso em: 9 nov. 2018.

OLIVEIRA, E. C.; SCOPEL, E. G. Uma década do Proeja: sua gênese, balanço e perspectivas. HOLOS, [S. l.], Ano 32, v. 6, p. 120-144, out. 2016. DOI: https://doi.org/10.15628/holos.2016.4998. Disponível em: https://bit.ly/2Hls1OO. Acesso em: 9 nov. 2018.

RIEGER, M.; ALEXANDRE, I. de J. Educação de Jovens e Adultos: o retorno das mulheres à escola. Revista Eventos Pedagógicos, $[S$. l.], v. 2, n. 2, p. 167-170, ago./dez. 2011. Disponível em: https://bit.ly/37jKUvN. Acesso em: 5 dez. 2018.

SANTOS, P. dos. Trajetórias juvenis de mulheres em privação de liberdade e experiências escolares: os sentidos produzidos nos encontros e desencontros com a escola. In: REUNIÃO NACIONAL DA ANPED, 37. Florianópolis, 2015. Anais [...]. Florianópolis: UFSC, 2015. p. 1-17. Disponível em: https://bit.ly/37lel0O. Acesso em: 5 dez. 2018.

SARTORI, A. T.; MENDES, L. Z. A reescrita como processo: as vantagens de uma segunda versão tardia. Revista do Gel, São Paulo, v. 13, n. 3, p. 130-157, 2006. DOI: https://doi.org/10.21165/gel.v13i3.1462. Disponível em: https://bit.ly/38lbYMM. Acesso em: 26 jun. 2019.

SHIMAZAKI, E. M. et al. O trabalho com o gênero textual História em Quadrinhos com alunos que possuem deficiência intelectual. Revista Brasileira de Educação Especial, Bauru, v. 24, n. 1, p. 121 142, jan./mar. 2018. ISSN 1980-5470. DOI: http://dx.doi.org/10.1590/s1413-65382418000100010. Disponível em: https://bit.ly/2UODjDc. Acesso em: 5 dez. 2018.

SILVA, I.; FARIAS, V. L. C. Os alunos do Proeja no IFRN Campus Currais Novos como usuários do serviço de empréstimo da biblioteca. HOLOS, [S. l.], Ano 25, v. 3, p. 191-200, jan. 2010. Disponível em: https://bit.ly/39yygeb. Acesso em: 9 nov. 2018.

SILVA, M. R. da. A política de integração curricular no âmbito do Proeja: entre discursos, sujeitos e práticas. Ensaio: Avaliação e Políticas Públicas em Educação, Rio de Janeiro, v. 19, n. 71, p. 307-326, jun. 2011. DOI: http://dx.doi.org/10.1590/S0104-40362011000300005. Disponível em: https://bit.ly/39G6JYn. Acesso em: 9 nov. 2018.

SILVA, M. R.; JORGE, C. M. O reencontro dos sujeitos adultos com a escola: significados e tensões no âmbito do Proeja. Educação e Sociedade, Campinas, v. 39, n. 142, p. 55-71, jan. 2018. DOI: http://dx.doi.org/10.1590/es0101-73302017137347. Disponível em: https://bit.ly/2SkspTY. Acesso em: 9 nov. 2018.

SILVA, S. G. et al. Políticas educacionais: aproximações entre Ensino Médio, EJA e Educação Profissional. RIAFE, [S. l.], v. 12, n. 1, p. 278-293, jan./mar. 2017. e-ISSN: 1982-5587. DOI Prefix: 10.21723/riaee. Disponível em: https://bit.ly/2SERAzr. Acesso em: 5 dez. 2018. 
SOARES, A. C.; LOGUERCIO, R. de Q.; FERREIRA, M. A possibilidade de produção de saberes docentes na EJA/RS: rascunhos e desenhos. Revista eletrônica de Educação, [S. l.], v. 5, n. 1, p. 318, maio 2011. ISSN 1982-7199. Disponível em: https://bit.ly/2volXSN. Acesso em: 5 dez. 2018.

SOARES, S. S. Compreensões sobre formação docente no âmbito do Proeja. In: CONGRESSO NACIONAL DE EDUCAÇÃO EDUCERE, 12. Curitiba, 2015. Anais [...]. Curitiba: PUC, 2015. v. 1. p. 33606-33621. 1 CD-ROM.

SOUZA, E. O.; REIS, R. Juventudes na Educação de Jovens e Adultos: contradições entre suas conquistas como sujeitos de direitos e os silenciamentos nos espaços escolares. HOLOS, [S. l.], Ano 33, v. 3, p. 98-109, ago. 2017. Disponível em: https://bit.ly/2SJkgHu. Acesso em: 5 dez. 2018.

TAVARES, P. A.; SOUZA, A. P.; PONCZEK, V. Uma análise dos fatores associados à frequência ao Ensino Médio na Educação de Jovens e Adultos (EJA) no Brasil. Workingpaper 351, CMICRO, n. 25, dez. 2013.

TELES, L. F. Produção artística digital colaborativa e aprendizagem curricular no projeto ProejaTransiarte. HOLOS, $[S . \quad$ l. $]$, Ano $30, \quad$ v. 2 , p. 98-109, fev. 2014. DOI: https://doi.org/10.15628/holos.2014.1972. Disponível em: https://bit.ly/39oH2eu. Acesso em: 9 nov. 2018.

VITORETTE, J. M. B.; CASTRO, M. D. R. O Programa de Integração da Educação Profissional com a Educação Básica na Modalidade de Educação de Jovens e Adultos (Proeja) no IFG - Campus Goiânia: um percurso contraditório na construção do direito à educação. HOLOS, [S. l.], Ano 32, v. 2, p. 301-311, abr. 2016. DOI: https://doi.org/10.15628/holos.2016.2798. Disponível em: https://bit.ly/39ASfsJ. Acesso em: 9 nov. 2018.

VITÓRIA, F. B.; NOGUEIRA, V. dos S. Educação Profissional integrada ao Ensino Médio na modalidade de Educação de Jovens e Adultos: caminhos e contradições. Revista Espaço Acadêmico, Maringá, v. 15, n. 176, p. 99-111, 2016. Disponível em: https://bit.ly/31OHRL2. Acesso em: 20 set. 2018.

ZEN, E. T.; OLIVEIRA, E. C. O projeto integrador e a centralidade do trabalho para a formação humana no Programa de Integração da Educação Profissional com a Educação Básica na Modalidade de Educação de Jovens e Adultos (Proeja) IFES Campus Vitória/ES. HOLOS, [S. l.], Ano 30, v. 2, p. 134-142, fev. 2014. Disponível em: https://bit.ly/2UOSZpM. Acesso em: 9 nov. 2018. 